\title{
A Vision that Transcends Time \\ Remembering Dr Jackie Kirk
}

\author{
Zainul Sajan Virgi
}

$\cos 80$

Although I am the 2009 Jackie Kirk Fellow, it was only through her words and her work that I had the privilege of getting to know Dr Jackie Kirk so I feel a sense of loss in not having had the opportunity to hold dialogues and debate with someone who had accomplished so much good in the world in such a short time. I know I would have learned even more from her in person. In her writing, it is evident that Jackie's happiness and joy arose from ensuring that all those who were marginalized were not forgotten, and, more importantly, were equipped with the tools to begin the process of accessing a better life. We can only hope to carry on the tremendous work that had already been undertaken by Jackie in order to pay tribute to her life, her spirit and her passion. She will be equally missed by those who were fortunate enough to have worked with her and those who come to know her through her work.

Dr Jackie Kirk's exemplary work related to advocacy for girls in order to help them access a higher quality of life through education. Her untiring spirit, tenacity and generous commitment to girls has influenced and reinforced the direction of my research. The tributes to Jackie that poured in from all corners of the world - from Canada and the United States to Thailand, and from Afghanistan to Australia-spoke to the global impact of her work. Indeed, her influence on so many stakeholders was also evident in the resounding sadness felt in academic institutions and in multi-lateral, non-governmental and grassroots organizations around the globe at the loss of a colleague, friend and partner dedicated to improving the quality of life of girls around the world. Jackie's commitment to ensuring that girls from post-conflict situations were able to access a better life through the provision of relevant education in safe schools, helped by female role-models and mentors was remarkable and her attempts to ensure that their teachers received relevant and applicable training clearly demonstrated to me Jackie's sensitivity, awareness and understanding of the multiple challenges faced by girls living in refugee camps and/or post-conflict 
situations. Moreover, Jackie's holistic approach in developing programs with her colleagues as well as beneficiaries of the program that address both access and retention of girls in school crystallizes for me her commitment to the value to girls of quality and relevant education. As a result of this, I am even more drawn to her work since I strive to be an advocate of sustainable, relevant and holistic solutions that are designed by the people for the people.

Jackie's work focused on children in refugee camps in post-conflict situations but there are many similarities between these girls and the ones with whom I work in Mozambique. The outcomes and experiences as well as the opportunities afforded to girls who have lived through the horrors of war, death and violence and who are now living in refugee camps are similar to those of the girls I am working in Mozambique whose lives have little quality as a result of abject intergenerational hardship. ${ }^{1}$ Poverty has resulted in their marginalization because of both gender and class, as well as their inability to access power in order to exploit economic opportunities, quality education and health-all of which would lead to a higher quality of life. The girls living a life of intergenerational hardship are also at greater risk of violence, rape and HIV and AIDS, as are the girls living in refugee camps, because of the minimal protection afforded to both groups. Jackie's thoughtful insights, therefore, are enormously relevant to my research, adding, as they do, new layers of understanding of the complex challenges related to girls living a marginalized life.

For the past six months, I have had the honour of working with ten girls between the ages of ten and fifteen who face economically challenging circumstances,in Maputo, Mozambique. My research focuses on the type of capacity required by these ten girls for them to begin the process of accessing a higher quality of life according to the priorities they have outlined.

I have used photography and video work to try to see life through the eyes of young students at a local girls' school in order to better understand the complex challenges related to the reality of their lives. This photography and video work enabled the girls to uncover, debate and understand the multiple barriers they themselves encounter in trying to improve their quality of life. As one girl said, "I now really see myself. I can now see the similarities in the lives of my grandmother, mother and aunties. I don't want the same life for myself." Another said, "What 
I once perceived as normal within my community, I now see as a challenge that needs to be addressed." It was clear to me that the girls had begun to become aware of themselves, their community, their present situation and their future. Critical awareness is, after all, the foundation for achieving sustainable solutions. With this in mind, I continue with my search for other academics who have similar beliefs while engaging others who will continue to provoke and stretch my thinking.

I draw on Jackie's work in Afghanistan, Pakistan, Australia, Ethiopia and Canada in order to provide me with a deeper understanding of the multiple issues faced by students and teachers living in post-conflict situations and/or refugee camps. Jackie highlighted the importance of culture and mother-tongue in enhancing intergenerational relationships in her work with Afghan teachers living in Montreal (Kirk 2006). The parents in Mozambique express the mistrust they have for schools that dismiss or diminish the value of culture. As a result of this mistrust, it is girls who are being denied the opportunity to either access or remain in school. The importance of engaging both community and educators therefore cannot be underemphasised. Jackie's work underscored this point adamantly.

In Jackie's work in Afghanistan, she also highlighted the importance of weaving culture into solutions in order to ensure that girls attend schools regularly. For example, in some of the villages in Afghanistan, parents felt comfortable only with same sex classrooms, whereas in others, because all the children came from the same village, a mixed classroom was acceptable (Kirk and Winthrop 2006). Jackie's commitment to better understanding the role of culture in education is of fundamental value in developing on-going dialogue and communication particularly between communities that have previously been denied education and educational systems advocating for the importance of their children attending school. I believe that it will be this open communication, which allows for debate and dialogue between and among the community, school, policy makers, students and teachers, that will enable girls (who may be of the first generation to attend school) to complete their education and access a higher quality of life.

Recently, I have begun to read the work Jackie did that focuses on developing minimum standards of quality of education for refugee children. The work, undertaken in Australia, has provided me with the opportunity to learn about practical design and evaluation tools that, if 
used optimally, could result in a higher quality of education (Kirk and Cassity 2007). I would like to explore these possibilities further. The shortage of qualified teachers, the enormous influence teachers have on students, as well as the lack of appropriate teacher development programmes were also the focus of Jackie's work in Ethiopia and Afghanistan (Winthrop and Kirk 2006). These are the same challenges being faced by Mozambican girls, particularly those living in intergenerational hardship. I found the observations made by Kirk and Winthrop to be particularly astute in relation to the Ethiopian teachers who are themselves refugees teaching fellow refugees. These teachers had insight into, and understanding of, the students' challenges and aspirations and were able to address them in a meaningful manner. This interested me greatly in relation to the comments made by the girls in Mozambique about how teachers mistrusted them when they arrived late at school because of the chores they had to complete at home, including fetching water. Furthermore, the lack of understanding by the teachers of the complex challenges faced by girls living in abject economically challenging circumstances made me consider the value and importance of developing a teaching cadre from within similar communities and/or ensuring that teachers coming from difference life experiences have a deep sense of empathy and understanding of the students' lives. To walk in their neighbourhoods, to try to understand, deeply, the strengths and challenges of the students' communities, families and lives, would be, I think, of paramount importance, particularly because of the significance a teacher particularly has in the lives of children who have been marginalized.

In one of my favourite photos (see next page), Enya's expression as she takes the photo is very special: the look of awe and wonder is priceless. The photo also represents the underlying message we try to communicate during our field work-how we all learn from each other, how we all have ideas that are important and, most significantly, how we must listen to each other's ideas and find strength in all the diverse perspectives. In seeing this picture of some of the girls I have had the privilege to meet and work with-their smiling and obviously determined faces, their sense of awe and wonder as they learn new skills and explore the wisdom, ingenuity and creativity that is hidden deep within themselves-you would, perhaps for the first time, see past the economic challenges that are often linked with children living in Africa 


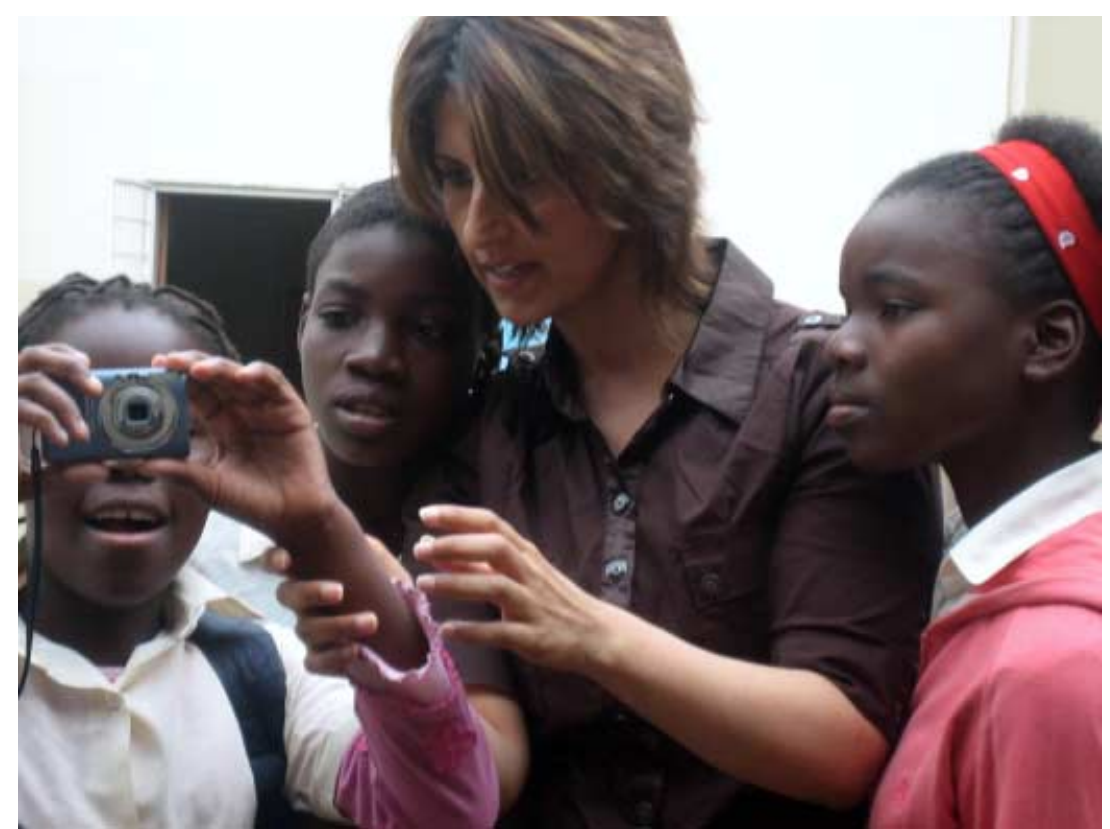

and depicted in numerous photos taken by non-governmental organizations, journalists and even academics. If you were present with me during the numerous lively discussions and debates that the girls, my research assistants and I have had, you would quickly see the depth of the ideas presented by these ten amazing girls, their diverse knowledge, their unique and practical ideas for solutions to challenges in their lives and community, as well as their dreams and hopes for a better life including access to clean water, jobs for their families and the opportunity to access higher education for themselves. More often than not, stories emerging from Africa focus on the deficit, the challenges, but there is more to Africa than just the challenges: there is life being born every day and filled with hope and dreams. There is ingenuity among youth and adult alike in creating incredible solutions with limited resources and, most importantly, there is energy among those who have the least economically to move forward and to access a higher quality of life. These are the stories that must also be communicated in order to ensure that, as the Nigerian author Chimamanda Adichie suggests, we do not perpetuate the limiting perspective found in one single story in relation to an entire nation or group of people. 
In reading Jackie's work, I feel that she was engaged in a journey in which she was determined to tell a different story of the refugee children and the teachers working in refugee camps. I felt that along with the challenges experienced by both, Jackie worked consciously to uncover the many hidden strengths, the wisdom and the creativity. She did this through the development of working partnerships in which multiple stakeholders developed practical and sustainable tools based on the hope of a higher quality of life for the people as determined by them. I find such a vision exciting and inspirational and one that will remain a central part of my journey in Mozambique. Thank you, Dr Jackie Kirk, for being the visionary you were! My deepest regret is not having met you. I extend my sincerest condolences to your family.

$\cos$

Zainul Sajan Virgi is a PhD candidate in the Department of Education at McGill University. Her research is based in Maputo, Mozambique. She is working with girls between the ages of 10 to 15 with the aim of understanding what type of capacity would trigger meaningful and sustainable improvement in the quality of the lives of girls facing complex and multiple challenges related to abject intergenerational hardship. zainul.sajanvirgi@mail.mcgill.ca

\section{Note}

1. I am trying to develop a term that captures the holistic nature of abject intergenerational poverty. The term 'poverty' usually conjures up images and/or ideas of being poor in mind, spirit, thought, ideas, spirit and wisdom, whereas the girls facing these challenging circumstances are rich in thought, mind, spirit, wisdom and ideas. Hence, I use the term 'intergenerational hardship' instead of 'intergenerational poverty'.

\section{References}

Adichie, Chimamanda. 2009. “The Danger of a Single Story”. http://www.ted.com/ index.php/talks/chimamanda_adichie_the_danger_of_a_single_story.html (accessed 20 January 2010).

Kirk, Jackie. 2006. "Transferring Cultural Knowledge and Skills: Afghan Teachers for Afghan Students in Montreal." Refugee: Canada's Periodical On Refugees 23, no. 1: 45-60.

Kirk, Jackie, and Elizabeth Cassity. 2007. "Minimum Standards for Quality Education for Refugee Youth.” Youth Studies Australia 27, no. 1: 50-56. 
Kirk, Jackie, and Rebecca Winthrop. 2006. "Home-Based Schooling: Access to Quality Education for Afghan Girls." Journal of Education for International Development 2, no. 2: 1-9.

Winthrop, Rebecca, and Jackie Kirk. 2005. "Teacher Development and Student Well Being." Forced Migration Review, University of Oxford 22: 18-22. 